\title{
The Analysis of Organization of Dismantling Methods of End-of-Life Vehicles for the Needs of Recycling
}

\author{
Viktor Kryaskov ${ }^{1, a}$, \\ ${ }^{1}$ Transport Systems Institute, Nizhny Novgorod State \\ Technical University n.a. R.E. Alekseev, Minin str., 24, \\ Nizhny Novgorod, 603950, Russian Federation \\ a viteakvg@mail.ru
}

\author{
Sergey Gagunov²,b, \\ ${ }^{2}$ Co Ltd. "Automobile plant "GAZ”, Lenina ave., 88, \\ Nizhny Novgorod, 603004, Russian Federation \\ bgagunovsa@gaz.ru
}

\author{
Anton Tumasov ${ }^{* 1, \mathrm{c}}$ \\ ${ }^{1}$ Transport Systems Institute, Nizhny Novgorod State \\ Technical University n.a. R.E. Alekseev, Minin str., 24, \\ Nizhny Novgorod, 603950, Russian Federation \\ c anton.tumasov@gmail.com
}

\begin{abstract}
This paper proposes a general overview of existing technologies and methods of organization of disassembly of end-of-life vehicles at the end of their operational stage. The experience of countries with the most effective ELV recycling systems has been analyzed in order to develop recommendations for the GAZ Group (the largest light commercial vehicles producer in Russia) on creating the producer's Strategy on implementing the requirements of EU Directive 2005/64/EU. It is mentioned that the depth of material separation depends on what equipment is used at pretreatment processes and how the shredder residue is operated afterwards.
\end{abstract}

Keywords: end-of-life vehicle; disassembly; recycling; material extraction; dismantling technologies

\section{Introduction}

Currently there are only about 4 countries and one region in the world where well organized end-of-life vehicle (ELV) recycling systems are functioning under governmental control. These are Japan, USA, China, Korea and countries of European Union. The main background of creating such systems is that on mentioned territories more than $50 \%$ of worldwide automotive pool is concentrated and this preponderance becomes more and more significant.

Countries with legislative ELV systems commonly set a target for recovery rates for about $95 \%$ recovery from 2015 . These rates can be reached by both methods of improvement of the vehicles design using the design for recycling process and by deepening the separation processes at the stages of treatment. Finally the depth of material separation is the most important factor in the quality and quantity of secondused materials extracted form an ELV. In this paper the author is trying to give an overview of existing and more frequently used methods of ELV treatment.
Despite some differences in dismantling methods and equipment, in general technological chain of processing and recycling ELV can be presented as (Fig. 1):

- acceptance, cleaning;

- drying, dismantling;

- shredding;

- sorting and preparation.

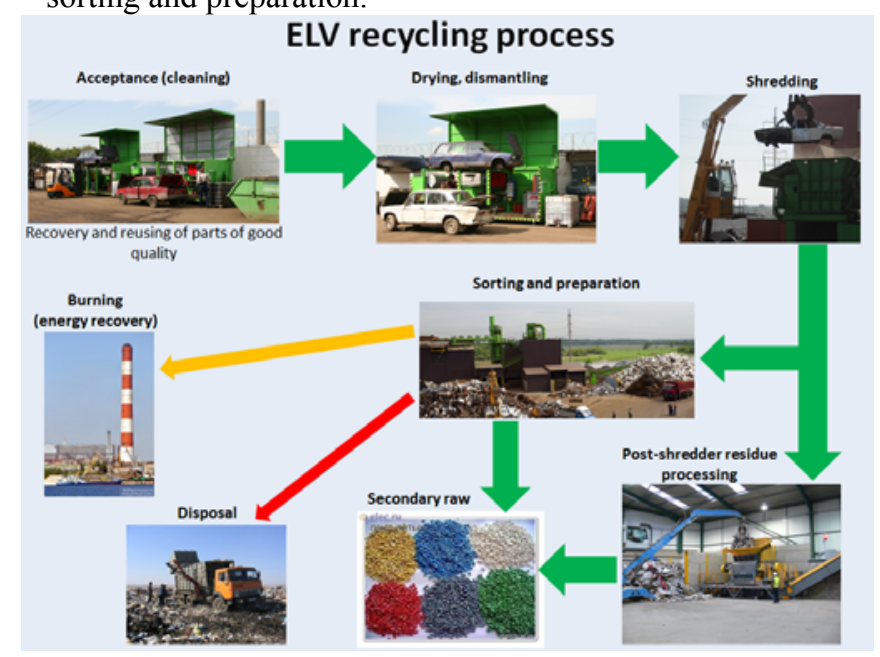

Fig. 1: The technological chain of processing and recycling ELV

\section{Acceptance and cleaning}

After deregistration ELV is transported to the recycling facility. Usually acceptance is conducted by a specialized organization or by dealer that should prepare the vehicle for the forward operations. In particular, it is important to remove dirt, dust and other contaminants accumulated in inaccessible locations of the vehicle during operation. Depending on the scale and economical abilities of the company different equipment from simple water jet 
machines to hydro-abrasive installation are used for these purposes.

\section{Drying and dismantling}

The dismantling process for the needs of recycling is largely determined by the further processing technology and also by the incoming volume of ELVs.

One of the latest and high efficient technologies in the field of automotive recycling is processing post-shredder residue. It allows to not pay so much attention to the depth of disassembly process. A lot of non-metal components can be left on the ELV because further post-shredder processing ensures their recycling and does not influence on real rates of recyclability of the vehicle.

When the incoming volume of ELV is quite large it is convenient to use the conveyor method of disassembly. It largely increases the dismantling speed and reduces the burden on workers. Certainly it suggests completely different level of equipment and tooling but the whole disassembly process of an ELV takes just few minutes. The main disadvantage of this technology is that the smooth functioning of such facilities requires increased amounts of ELV. This factor is the main reason why conveyor methods are used only in regions with high quantity of vehicles.

So, after preparing for dismantling the drying of ELV is produced. It suggests mandatory drainage of absolutely all of operational liquids (motor, transmission and hydraulic systems oils, liquids from coolant, brake and air conditioning systems, from shock absorbers and etc.). The vacuum equipment is the most frequently used for these purposes. It can be as a single stand with separate tanks as separate vacuum equipment for each type of liquid. The main requirements for this equipment is that liquids must be separated from each other and that the tanks should not allow leakage.

After drainage the ELV has to be dismantled. The strictest rules on conducting the ELV dismantling process are contained in the Directive 2000/53/EC. According to this document besides the operational liquids the following components must be removed from the vehicle at the stage of dismantling for the needs of recycling $[1,3]$ :

- batteries;

- gas equipment;

- tires and wheels (including spare wheel);

- all filters;

- exhaust gases neutralization system;

- potentially explosive components (eg, passive safety systems);

- fire extinguishers;

- glass.

Undermining of the airbag squibs is conducted on special stands with a remote control connected with the onboard computer of the vehicle.

Frequently the differences in construction of vehicles can create some problems during disassembly. In order to solve these problems regulatory documents of some countries (in particular, EU and Korea) include requirements for manufacturers to provide recycler companies with all necessary information regard the dismantling and separation of materials used in each model of produced vehicle. For example, according the EU Directive 2005/64/EC such information consists in quantity, placement and mass of components recommended for dismantling or dismantling of which is required by the legislation, method of their removal and material that they are consisted of. Such information should be indicated in specially created dismantling catalogues (guidelines) (Fig. 2).

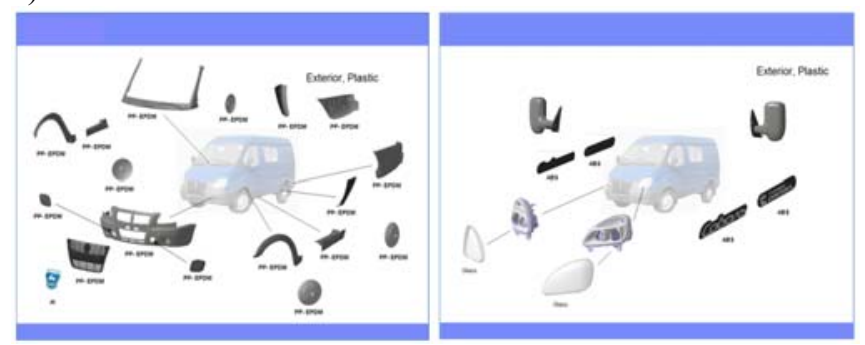

Fig. 2: The example of information consisted in dismantling catalogue

The equipment and tools that are used for the needs of dismantling before ELV recycling are the same as at vehicle service centers. Along with different hoists and stands, ordinary pneumatic wrench and spanners are used for unscrewing bolts and nuts, simple screwdrivers - for screws and etc. The exception is special tool for removing certain components. For example, the dismantling of windshield can be done by using a special metallic string with removable handles at both ends. After it is shoved between body pillars and the windshield two workers by pulling the string in turns cut out the glue on the whole contour and remove the windshield [4-7].

It is needed to consider certain unusual processes applied in different countries.

In Japan some types of mobile manipulators are widespread on ELV dismantling facilities. Such manipulators shown on the Fig. 3 allow a single operator to conduct a dismantling for recycling process even without necessity of other equipment. The process of preparation the ELV for shredding is conducted in the following way: at first, the vehicle must be dried by usual method (as described before) and then it enters the dismantling plot with a mobile manipulator.

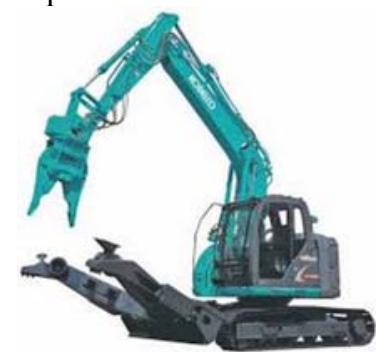

Fig. 3: The Japanese manipulator used in dismantling for recycling process 
The manipulator can be equipped with different applications depending of what the size and the structure of the component that must be removed from the vehicle. Thus, a great number of parts starting from small pipes and plastic panels up to windshield, doors, suspension elements, tires and etc. are removed and sorted according to the material that they are made of (Fig. 4). Furthermore by using a cutting tip it is possible to destroy the car body into several pieces in order to reduce energy costs during the shredder process $[8,9]$.

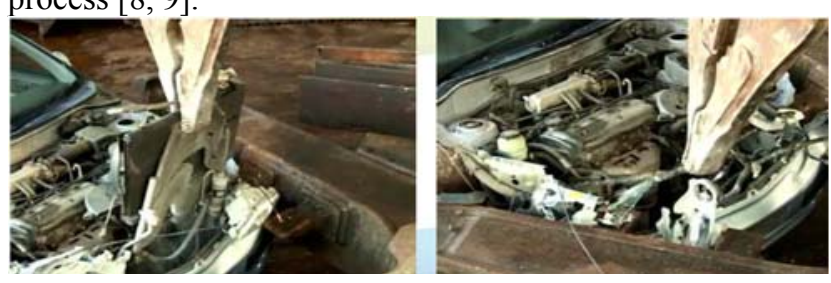

Fig. 4: Removing under-hood components of an ELV by using a mobile manipulator

The Chinese "VARY" company is another interesting example of managing an effective ELV dismantling process. The disassembly is organized in four stages [10]:

- evaluation and dismantling of components and assemblies that could be restored and reused as secondary parts (except engine, steering, transmission and frame as parts that are legislative forbidden to reuse);

- drainage of operational liquids;

- removing of dangerous components and harmful materials (airbags pyro-cartridges, fire extinguishers and etc.);

- dismantling of other components for usage as secondary raw.

This method allows to conduct the disassembly on a very compact territory and can be compared with the conveyor technology for its flow-type algorithm (Fig. 5).

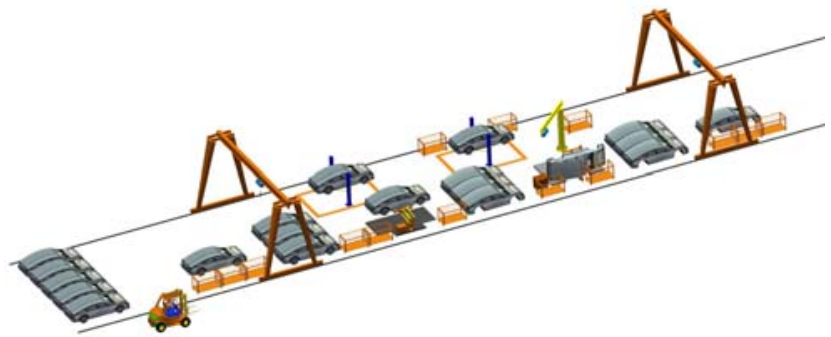

Fig. 5: The scheme of processing ELV on Chinese "VARY" organizations

\section{Shredding}

Shredder is a big hammer crusher machine designed special for grinding plastic (not fragile) material (Fig. 6).

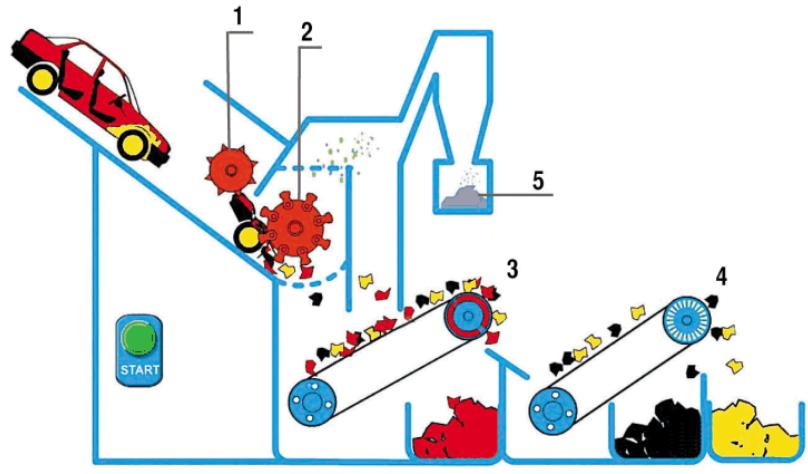

Fig. 6: The schematic representation of shredder: 1 - breaker, 2 - hammer crusher, 3 - pneumatic separation plot, 4 - magnetic separation plot, 5 - dust collector

The ELV body enters the breaker for the primary deformation and afterwards it is broken into pieces by the hammer crusher and the dust enters the collector. The resulting scrap is transported to the pneumatic and magnetic separation plots for the separation of non-ferrous and ferrous materials. Very often in order to reduce transportation and energy costs the ELV body is pressed before shredding.

As the result of shredder process usually three material flows are formed:

- ferrous metals;

- non-ferrous metals;

- plastic, elastomer and other material (mixed).

Certainly recycling of metals does not cause any big problems as the metal scrap is transported to metallurgical facilities where it is melted into new shapes. But this does not apply to the processing of non-ferrous mix or postshredder residue. Not so many years ago the post-shredder residue was a really big problem on the way to achieve highest RRR rates (RRR - recoverability, reusability, recyclability) and it was partially solved by the development of post-shredder separation technologies [2].

\section{Conclusions}

Based on the information above, we can conclude that one of the most important principles of conducting an ELV dismantling process are:

environmental safety waste management that is the background of legislative requirements for drainage equipment, storage of operational liquids and removal of hazardous substances;

there are two ways of achievement of the highest RRR rates in modern ELV treatment practice. The first consists in involving the post-shredder process that implies more difficult technological methods of material separation based on their chemical and physical properties. Despite the high efficiency and productivity this technology is not used very often because of the economic vulnerability. Most of the post-shredder plants work 
with additional financing. The second way is more common and lies in organization of the material separation as deep as possible on the stage of disassembly before shredding. Beside the ability to remove certain component a very important factors influencing on the separation depth are costefficiency and expediency. For example such a big component as a plastic bumper is not difficult to be removed and sold that cannot be said in regards to a small plastic bracket weighting about 10 grams.

the equipment and tools that are used for the needs of dismantling before ELV recycling are the same as at automotive service stations.

\section{ACKNOWLEDGEMENTS}

The research was done with the financial support of Ministry of Education and Science of the Russian Federation in the frame of the complex project "The establishment of the advanced technology production of ecological and resources-economy LCV" under the contract №02.G25.31.006 from 12.02.2013 (Governmental Regulation №218 from 09.04.2010).

\section{REFERENCES}

[1] Directive 2000/53/EC On End-of-Life Vehicles For The Period 20022005. Brussels, October 2007. 90 p.

[2] http://ec.europa.eu/environment/waste/pdf/study/annex3.pdf

[3] http://sertimet.uran.ru/tech_reg

[4] http://vaz2101.com/showthread.php?t=57033

[5] http://www.autosecret.net/avtosecret/556-remont-skolov-zamena-stekla

[6] http://www.bis.gov.uk/files/file30654.pdf

[7] http://www.info-autoglass.ru/info/technology/page200

[8] http://www.mai.org.my/

[9] http://www.mai.org.my/ver1/images/pdf/4aaefDownload/9Takahiro.pdf [10] http://www.varytech.cn/ 